\title{
Study on the Application of Situational Teaching Method with PBL in Clinical Teaching of Ectopic Pregnancy
}

\author{
YuanPan ${ }^{1}$, YangYu and Ruizhi Liu ${ }^{\text {a* }}$ \\ ${ }^{1}$ Reproductive medical center, First Hospital, Jilin University, Changchun city Jilin Province,130021 \\ adghrtgrd@163.com \\ *The Corresponding author
}

\section{Keywords: PBL; Situational approach; Ectopic pregnancy; Clinical teaching}

\begin{abstract}
Objective: Situational teaching method with PBL is applied in the clinical teaching of patients with ectopic pregnancy. Its clinical curative effect is discussed and analyzed. Methods: A total of 100 nursing students in our hospital were randomly assigned to two groups: the observation group and the control group. There were 50 cases in each group. The interns in the control group used the conventional teaching methods. The observation group used the situational teaching method with PBL. The improvement effect and satisfaction of the control group and the observation group were analyzed. Results: Compared with the control group, the clinical knowledge and operation ability of the interns in observation group were all higher, and the teaching effect of the two groups was significant $(\mathrm{P}<0.05)$. Compared with the control group, the observation group had higher satisfaction with clinical nursing teaching, teacher and patients, and the difference between groups was greater $(\mathrm{P}<0.05)$. Conclusion: The situational teaching method with $\mathrm{PBL}$ has obvious application effect in the teaching of clinical ectopic pregnancy. It has more significant clinical effect than the conventional teaching method. It has wide application value in clinical practice and is worthy of promotion.
\end{abstract}

As a common acute abdomen in obstetrics and gynecology, ectopic pregnancy is characterized by high prevalence, acute onset, and high risk. Therefore, timely and correct diagnosis and treatment of ectopic pregnancy is the essential skill that obstetricians must master. They can also be diagnosed or excluded when other specialists in surgery, internal medicine, etc. perform differential diagnosis of abdominal pain. As a key subject in the syllabus of obstetrics and gynaecology, ectopic pregnancy requires students to master and cope ${ }^{[1]}$. However, because most of the ectopic pregnancy patients in clinical practice are emergency care and involve "privacy", it is difficult for teachers to provide students with real cases in the probation, and it is impossible to integrate theoretical content of the classroom into clinical practice. The ectopic pregnancy care work of obstetrics and gynecology is more complicated, coupled with the boring and cumbersome nursing knowledge, which brings great difficulties to the clinical teaching work. Therefore, nursing students have obvious obstacles in learning related knowledge and cannot successfully and efficiently achieve learning goals. At the same time, the pathophysiological changes of ectopic pregnancy cause most medical operations to involve genital organs in female patients. As medical workers, they need to provide satisfactory medical services, but as the teachers in teaching hospitals, they should also meet students' requirements and complete teaching practice according to the syllabus, to ensure the quality of teaching. There are contradictions between these two requirements ${ }^{[2]}$. There are many defects and inconveniences in the implementation, especially the lack of a series of steps, such as students' participation in the learning process and interaction with the patients. However, it is a new trend to successfully conduct teaching work, ensure the cultivation of qualified medical students, and develop new teaching methods. PBL takes the problem as a basic method of teaching, to make students get into the actual state of learning problems, motivate students' learning motivation and interest, and actively cultivates students to find problems and problem solving skills, teamwork capabilities. It has become a new type of teaching method widely used in the world. A discussion group composed of several students and a guide teacher is mainly used. Students think, ratiocinate and analyze around the questions, so that teachers guide students to complete the teaching goals, targeted to improve nursing students' ability to innovate and self-learning ability ${ }^{[3]}$. 
With the deepening reform of higher education teaching research, PBL teaching method can not only cultivate the overall quality of students, but also better cultivate the students' ability to find problems, analyze problems, and solve problems, and effectively combine the learned theory with clinical practice. Situational teaching mainly brings students into concrete clinical nursing practice to provide students with sufficient practice opportunities, which can improve the promotion of practical ability. Therefore, in the clinical teaching of ectopic pregnancy, this paper uses situational teaching method with PBL to examine its effect and analyze it.

\section{Materials and methods}

General data. During the period of 2017.10.8-2018.1.1, 100 nursing students who came to practice in our department of gynecology were divided into a control group and an observation group randomly. There ages were between 23 and 27 years old, with an average age of (25.2 \pm 2.3$)$ years old. There 11 males and 39 females in the control group. The observation group included 9 males and 41 females. The statistical data of gender, age, theoretical scores, and internship time these two groups were analyzed and compared with each other. There was no significant difference between these two groups. The $\mathrm{P}$ value was greater than 0.05 , which was comparable.

Method ${ }^{[4-7]}$. The nurse interns in the control group took conventional ectopic pregnancy clinical teaching program of the hospital, and the observation group nurses used the situational teaching method with PBL. The specific operation plan was as follows: the teacher gave sufficient time to students for the case analysis and discussion before teaching. The nursing students firstly collected relevant data, formulated the corresponding plans and implemented goals, and finally determined the plan after discussions with the guiding teacher. Teacher conducted a focused analysis of typical issues. Teachers and interns then practiced the case, allowing the nurse to operate alone and the teacher to supervise the independent operation of the students. Corresponding nursing interventions were completed and the determined cases were discussed with teachers jointly to report the case. The clinical teacher further summarized, emphasized the learning focus and the difficult points according to the learning objectives to guide the students to think and summarizes the learning experience in the learning process. Their cases closely followed the practice outline and highlighted the key points according to the characteristics of ectopic pregnancy, to avoid exceeding the scope of learning ability and losing interest in learning.

Assessment Criterion. The situational teaching method with PBL is applied to the clinical effects of nurse students training in the case analysis of ectopic pregnancy and evaluated their teaching effects. The two groups of nursing students' academic performance, such as theoretical assessment, skills assessment performance, and comprehensive quality performance, were compared with full scores of 100, the higher, the better. According to the requirements of our hospital system, satisfaction survey was conducted to evaluate teaching satisfaction.

Statistical processing method. The two groups of results taught in different ways were analyzed and compared using SPSS 14.0 statistical software. Measured data were expressed with $(\mathrm{x} \pm \mathrm{s})$ using t-test; enumeration data were expressed as rate $(\%)$ and enumeration data was expressed with $(\%)$, using $\chi 2$ to inspect, . There was significance in the differences between groups with $\mathrm{P}<0.05$

\section{Results}

Score comparison between two groups. From the results, after the assessment, the theoretical scores of the nurses in the control group were $(75.6 \pm 14.3)$ points, the skills scores $(80.4 \pm 13.2)$, and the assessment results of the comprehensive quality were $(73.1 \pm 11.7)$. The theoretical scores of patients in the observation group were $(90.5 \pm 14.5)$ points, the scores of skills assessment were $(92.3 \pm 12.5)$, and the assessment results of comprehensive quality were $(91.8 \pm 16.1)$. There was a significant difference between the groups in their assessment results $(\mathrm{P}<0.05)$. As shown in Table 1. 
Table 1 Score comparison between two groups

\begin{tabular}{ccccc}
\hline Group & $\mathrm{n}$ & $\begin{array}{c}\text { Theoretical } \\
\text { score }\end{array}$ & Skill score & $\begin{array}{c}\text { Comprehensive } \\
\text { quality }\end{array}$ \\
\hline $\begin{array}{c}\text { Observation } \\
\text { group }\end{array}$ & 50 & $94.45 \pm 21.53$ & $96.32 \pm 22.34$ & $95.84 \pm 22.19$ \\
$\begin{array}{c}\text { Control group } \\
50\end{array}$ & $78.55 \pm 18.33$ & $81.37 \pm 19.22$ & $83.21 \pm 20.17$ \\
\hline
\end{tabular}

Satisfaction comparison. From the results, compared with the control group, the satisfaction of the observation group, the satisfaction of the teaching teacher, and the satisfaction of the patients in clinical teaching of ectopic pregnancy were significantly improved, and the difference between the groups was significant $(\mathrm{P}<0.05)$, see Table 2.

Table 2 Satisfaction comparison between two groups

\begin{tabular}{ccccc}
\hline Group & $\mathrm{n}$ & $\begin{array}{c}\text { Satisfaction of clinical } \\
\text { teaching method }\end{array}$ & $\begin{array}{c}\text { Satisfaction of } \\
\text { teachers }\end{array}$ & $\begin{array}{c}\text { Satisfaction of } \\
\text { patients }\end{array}$ \\
\hline $\begin{array}{c}\text { Observation group } \\
\text { Control group }\end{array}$ & 50 & $45(90 \%)$ & $43(86 \%)$ & $47(94 \%)$ \\
\hline
\end{tabular}

\section{Discussion}

Training teachers focuses on training students to proactively identify problems and actively find solutions of problems. The purpose is to help nurse students to connect theoretical knowledge with related practical experience in the shortest possible time, deepening and expanding the theoretical knowledge of the classroom to help the nursing interns to face the patients with specialized technology and operation level, and enhancing their sense of social responsibility. The quality of teaching work has a direct impact on the working level of nursing interns. Therefore, the choice of teaching mode is of utmost importance.

The PBL teaching method always regards students as the main body of teaching activities, taking questions as the basis, students as the main body, and teachers as the guide. This method is widely used in clinical nursing teaching in the field of modern teaching. The teacher designs and deals with real-life case-related issues, and extract typical examples. The interns collect the data information by using case data and literature query and other methods under the expected scenario hypothesis to integrate learning objectives into relevant issues so that students can jointly solve problems through independent inquiry and group assistance. Students need to master relevant knowledge in solving problems, and it is also conducive to cultivate nursing interns' problem-solving abilities and self-study awareness in the teaching process, which is mainly applicable to the more common typical diseases in clinical practice ${ }^{[8]}$. The situational simulation teaching method is mainly based on practical teaching. On the basis of the case teaching method, students' theoretical knowledge, practical skills, and expression communication skills can be comprehensively trained and developed by simulating various real-life scenarios to guide nursing interns to independently assess patient care and discuss specific care programs and draw conclusions. At present, the situational simulation teaching method in medical education is more applied in the field of nursing, but it lacks systematic research and evaluation. It has completely broken through the traditional nursing teaching methods and its greatest advantage in the real implementation of the case is to propose and solve problems, collect data, as well as conduct program demonstration and evaluation summary simultaneously ${ }^{[9-10]}$. It enhances learning initiative and changes the traditional teaching mode, so that nurse interns turn to be good at discovering, thinking, actively consulting information for independent thinking to gain knowledge from passive acceptance, so that students master a whole set of nursing mode, which not only enhances their logic thinking ability and self-learning ability, but is more conducive 
to integrate ectopic pregnancy knowledge with practice by the nurse interns. In teaching, teachers only play a leading role. Although they cannot let students master all the knowledge, the implementation of teaching model is based on the purpose and contents of the teaching. The self-learning mode is started. The learning is set in various situations so that students can cooperate with each other to solve problems and reduce dependence on teachers, which can not only actively mobilize learning motivation and cultivate interest, but also help cultivate the awareness of nursing interns in the future, thus they can take the initiative to participate in discussions, and improve their learning ability. It also helps the teachers find their deficiencies and problems timely, thereby improving the quality of teaching ${ }^{[11]}$.

The results of this study show that the scores obtained by the nurse interns in the observation group are higher than those in the control group, and the improvement effect is more obvious. There is statistical significance between the groups $(\mathrm{P}<0.05)$. Compared with the control group, the nurse interns in the observation group have higher satisfaction. There was a significant difference between the two groups $(\mathrm{P}<0.05)$, indicating that the combination of $\mathrm{PBL}$ and the situational teaching method has obvious effect in the teaching of clinical nursing in ectopic pregnancy. This method is helpful to achieve the purpose of teaching. It shows that the main advantage of combining PBL with the situational teaching method lies in the combination of theoretical knowledge and clinical practice, promoting the realization of teaching goals, and then improving the quality of teaching through the in-depth exploration of case issues. In the process of independent thinking and group discussion, students master high-level problem-solving abilities and continue to form a sense of independent learning, helping to form a virtuous competitive learning atmosphere in class.

In summary, for the problems existing in the clinical teaching of ectopic pregnancy, it has a significant effect on the improvement of teaching quality through continuous exploration and clinical validation, targeted and integrated teaching model, that is, situational teaching method with PBL. It shows the superiority of the comprehensive teaching method, and it is more conducive to training nurses' clinical coping ability. It has certain guiding value in clinical practice.

\section{References}

[1] Li Qin. Clinical Value Analysis of Case Teaching in Gynecological Clinical Nursing Teaching [J]. General Nursing, 2015,13(30):3087-3090.

[2] Li Renlan, Zhou Yi. PBL Teaching Method in the Application of Nursing for the Women in Stages of Labor [J]. Curriculum Educational Research, 2014, 17(12):242.

[3] Ding Yanping, Mu Xiaoyun, Wang Yibo. Situational Simulation Teaching with PBL Method in the Application of Clinical Obstetrics and Gynecology Training [J]. Nursing Research, 2014, 23(21): 2923.

[4] Cao Weiwei. Application and Experience of Case Teaching Method in Obstetrical Clinical Nursing Teaching [J]. Public Health, 2014, 8( 22) : 318-319.

[5] Wang Mingyang. Analysis of the Effect in Applying PBL Teaching Method in Clinical Teaching of Gynecological Nursing [J]. Journal of Contemporary Medicine, 2015,13 (16): 56-60.

[6] Zhang Ning. Application of PBL Teaching Method in the Clinical Teaching of Nursing [J]. Heilongjiang Medical Science, 2014,10(3):111.

[7] Liao Qin. Observation of the Application Effect of PBL Teaching Method in Clinical Teaching of Obstetrics and Gynecology [J]. Medical Theory and Practice, 9(5):409-411.

[8] Lin Min, Zhou Min, Lu Xiuqing. The Application of Situational Method with PBL in Nursing Teaching of Obstetrics and Gynecology [J]. The People's Liberation Army Nursing Journal, 2014, 16(12): 68-73.

[9] Guo Tianzhi, Tu Suhua, Yan Mei. Appli cation of Situational Method with PBL in Nursing Teaching of the Women with Ectopic Pregnancy, 2015, 28 (13): 1815-18117.

[10] Wang Bingbing, Yi Dongmei, Zeng Ying. Application of Situational Simulation Teaching Method in Teaching of Internal Medicine [J]. Chinese Journal of Medicinal Guide, 2012, 14(5): 917-918. 
[11] Meng Fanjie. The Practice and Thinking of Teaching Innovation in Obstetrics and Gynecology Nursing [J]. Public Health: Academic Edition, 2014, 18(10):329. 